\title{
"LÁ VEM A CIDADE"! ANÁLISE E CONSIDERAÇÕES SOBRE A EXPANSÃO URBANA DA CIDADE DE FEIRA DE SANTANA - BA ENTRE OS ANOS 2000 E 2015
}

\author{
Matheus Gomes da Silva; Telma Maria Sousa dos Santos \\ 1. Bolsista PIBIC/CNPq, Graduando em Geografia, Universidade Estadual de Feira de \\ Santana, e-mail: matheus19gomes@ hotmail.com \\ 2. Orientadora, Departamento de Ciências Humanas e Filosofia, Universidade Estadual de \\ Feira de Santana, e-mail: telmaarq@ yahoo.com.br
}

PALAVRAS-CHAVE: Espaço urbano. Expansão urbana. Urbanização

\section{INTRODUÇÃO}

No processo de produção do espaço, o homem se apropria da natureza afim de prover as suas condições materiais de existência. Deste modo, transforma a primeira natureza em segunda natureza, está já antropizada. Este processo de produção do espaço, seja urbano ou rural, se dá de forma contínua, através de ações políticas, sociais, econômicas e culturais, assim, cotidianamente o homem produz e/ou reproduz o espaço (CARLOS, 1994). Isto posto, a expansão urbana é evidência dessas ações, pois é oriunda da apropriação do solo pelo homem, culminando com a ampliação e modificação dos espaços de vida da população (OJIMA, 2008).

Entende-se que a cidade de Feira de Santana tem sua expansão territorial resultante desses processos inerentes à sociedade capitalista, em que áreas antes desocupadas estão sendo apropriadas por diversos agentes produtores do espaço e incorporadas no ciclo de reprodução do capital. Portanto, objetivou-se, portanto, analisar os fatores que impulsionaram a expansão territorial da cidade de Feira de Santana entre os anos 2000 e 2015. Para aí chegar, através de documentos oficiais e de imagens de satélite, foram identificadas e caracterizadas as áreas de expansão urbana da cidade e, posteriormente, mapeadas; concomitantemente, foi identificado o papel do Estado nesse processo, bem como as ações da iniciativa privada.

Isto posto, este trabalho poderá contribuir para ampliar o conhecimento sobre a própria dinâmica urbana da cidade, bem como evidenciar o papel do Estado e dos demais agentes produtores do espaço neste processo e suscitar questionamentos e reflexões sobre como a sociedade produz e reproduz o espaço urbano de Feira de Santana e quais rebatimentos ocorrem deste processo na vida cotidiana e na configuração territorial da cidade.

\section{MATERIAL E MÉTODOS OU METODOLOGIA (ou equivalente)}

Para realização desta pesquisa, inicialmente se fez a bibliográfica a respeito de temas inerentes a este trabalho. Paralelamente à pesquisa bibliográfica, foi feita uma consulta ao programa Google Earth, em busca de imagens de satélites de épocas variadas que revelaram a expansão urbana da cidade e o surgimento de novas áreas urbanizadas.

Também foram realizadas entrevistas com representante do poder público municipal para saber quais ações a prefeitura tem tomado a respeito da expansão da mancha urbana da cidade; conversou-se também como algumas imobiliárias e incorporadoras da cidade para se ter um vislumbre da ação destes enquanto agentes produtores do espaço e, por fim, foram colhidos dados no sindicato dos trabalhadores rurais de Feira de Santana a fim de se entender quais os rebatimentos do crescimento da cidade para as populações do campo

Após colhidos os dados primários, passou-se à fase de interpretação e sistematização dos mesmos para elaboração do texto final. 


\section{RESULTADOS E/OU DISCUSSÃO (ou Análise e discussão dos resultados)}

A partir de 2000, com a expansão do mercado imobiliário nacional, Feira de Santana começou a receber grandes investimentos no ramo, tanto da iniciativa privada, quanto do poder estatal dentro do programa "Minha Casa, Minha, Vida". Atrelado a isto está o arrefecimento do setor na capital do Estado, Salvador, onde entraves dificultaram o surgimento de novos empreendimentos. Neste cenário predominante na capital baiana, a solução encontrada para o mercado imobiliário foi investir em outras cidades do interior, que demandavam empreendimentos considerados "modernos", tais como condomínios fechados, bairros planejados, ou seja, novas tipologias do mercado para famílias de renda média e alta, conforme a Associação dos Dirigentes de Empresas do Mercado Imobiliário da Bahia (ADEMI, 2016).

Uma vez que nas áreas centrais, principalmente no interior do Anel Viário, não existiam grandes áreas para o padrão de construção imobiliária mais comum da cidade: as de tipo horizontal, os agentes produtores começaram a inserir os empreendimentos nas áreas limítrofes com o espaço rural.

Analisando diferentes períodos (figuras 1,2), nota-se que há uma orientação da expansão territorial da cidade. A cidade cresce, predominantemente, no sentido norte, nordeste e leste. Nas imagens de satélite abaixo, percebe-se tal dinâmica. Em destaque, de amarelo, é a Av. de Contorno, que circunda a área de urbanização já consolidada.

Figura 1: A: Mancha urbana de Feira de Santana em 2001. Nota-se, afora a área de ocupação já consolidada, o avanço da ocupação em direção às bordas norte e sul. B: Mancha urbana de

Feira de Santana em 2016. Nota-se a expansão territorial da cidade e parcelamento do solo intensificando-se nas bordas norte, nordeste e leste. Na borda oeste, ocupação rarefeita.
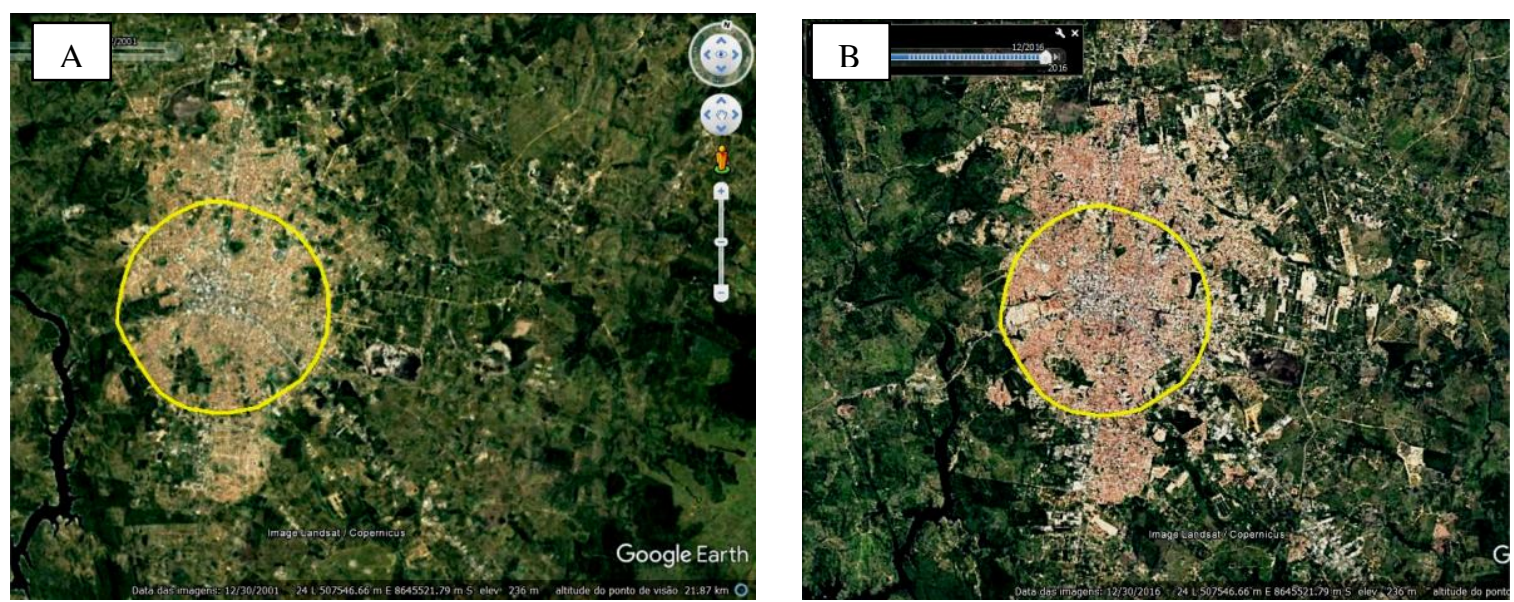

Fonte: Google Earth, 2017

Adaptado por: Matheus Silva, 2017.

A partir da abertura e pavimentação de importantes vias estruturantes, o mercado imobiliário abriu novos vetores de crescimento da cidade. Estas vias estruturantes, como Av. Transnordestina, Av. Fraga Maia, Av. Ayrton Senna, Av. Noide Cerqueira e da Av. Artêmia Pires de acordo com os dados colhidos em pesquisa de campo nas imobiliárias e incorporadoras da cidade, foram de fundamental importância para a construção dos condomínios e loteamentos habitacionais, pois facilita a mobilidade dos futuros moradores.

Por outro lado, não se pode deixar de discutir a participação da construção de residenciais populares do programa "Minha Casa, Minha Vida" em Feira de Santana. A 
distribuição espacial seguiu, em parte, a mesma lógica de valor do solo urbano. Estes empreendimentos, por sua vez, foram inseridos em áreas mais desvalorizadas da cidade: em bairros com pouca infraestruura urbana, de ocupação popular, como Mangabeira, Santo Antônio dos Prazeres e Conceição. Como aponta Santo, et al (2016), foram implantados 112 empreendimentos do MCMV em Feira de Santana entre 2009 e 2014, estes muito contribuíram para a expansão territorial da cidade, pois parte estavam sendo planejados ou construídos nas áreas que foram posteriormente incorporadas ao tecido urbano ou em bairros que ainda não tinham a área totalmente urbanizada, modificando, de forma inequívoca e categórica, a malha urbana feirense.

Como consequência de toda essa dinâmica da urbanização feirense, os limites urbanos foram extrapolados. Alguns vetores de expansão foram além dos limites oficiais do espaço urbano e se espraiaram pelas áreas rurais. A fim de regularizar tal situação, por meio da Lei Complementar $\mathrm{N}^{\circ}$ 075, de 20 de Junho de 2013, a cidade teve o perímetro urbano alterado pelo poder público municipal, redundando no aumento da área urbana. O perímetro anterior abarcava uma área de aproximadamente $176,10 \mathrm{~km}^{2}$ e a cidade era composta por quarenta e quatro bairros. Com a alteração, houve a inserção de áreas do espaço rural, perfazendo um acrescimento ao espaço urbano de $150,59 \mathrm{Km}^{2}$. Os novos bairros de Feira de Santana se encontram nas bordas da cidade (mapa 1). De acordo com a Lei, os novos bairros da cidade são: Cis Norte, Pedra Ferrada, Mantiba, Registro, Chaparral e Vale do Jacuípe.

Mapa 1: A nova configuração espacial da cidade de Feira de Santana-BA com os novos bairros

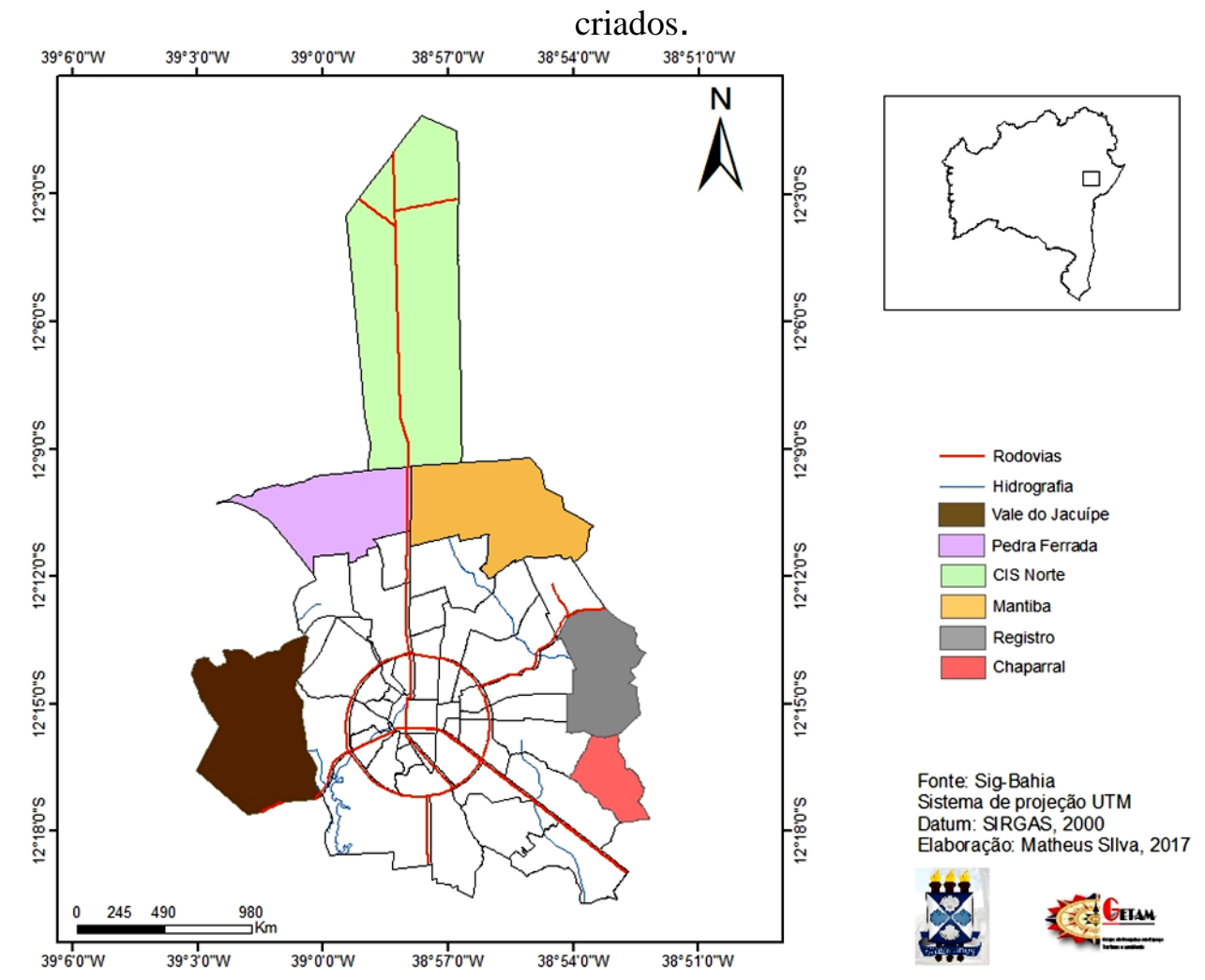

Os rebatimentos para as populações que já moravam nesses espaços antes do avanço imobiliário devem ser considerados. Quando da promulgação da Lei de alteração do perímetro urbano, as populações das áreas rurais que foram inseridas no tecido urbano questionaram tal ação do poder público sem consultá-las ou informá-las sobre tal intenção de 
diminuir a zona rural do município e aumentar o perímetro urbano. As populações foram excluídas desse processo de tomada de decisão

\section{CONSIDERAÇÕES FINAIS (ou Conclusão)}

Os principais fatores verificados durante a pesquisa e que sobremodo contribuíram para a expansão territorial da cidade de Feira de Santana concernem ao arrefecimento do mercado imobiliário no principal centro urbano do Estado, a capital, Salvador. Com isto, os agentes hegemônicos de produção do espaço buscaram novos espaços para reprodução e ampliação do capital. Estes espaços serão justamente as cidades do interior, como Feira de Santana.

A partir da chegada dessas incorporadoras na cidade, juntamente com as construtoras locais que já vinham executando ações nesse sentido, a mancha urbana se expande em decorrência da construção de empreendimentos, principalmente dentro do programa Minha Casa, Minha Vida, voltados para populações de baixa renda e que tem uma localização espacial específica, contribuindo, assim, para o recrudescimento das desigualdades socioespaciais. Além disso, tem-se a construção de empreendimentos de médio e alto padrão que são inseridos a fim de atender a demanda solvável da cidade.

Como as áreas dentro do Anel viário da cidade já apresentavam urbanização consolidada, são nas áreas no entorno que os empreendimentos irão ser inseridos, atrelados à abertura de grandes avenidas que contribuem para o crescimento urbano da cidade. Áreas antes periurbanas e rurais passam pelo processo de supervalorização fundiária provocando mudanças na dinâmica socioespacial e no conteúdo social.

\section{REFERÊNCIAS}

ASSOCIAÇÃO DOS DIRIGENTES DE EMPRESSAS DO MERCADO IMOBILIÁRIO DA BAHIA. Ademi-BA parte para o interior. Revista da Associação dos Dirigentes de Empresas do Mercado Imobiliário da Bahia, Salvador, ano 15, n.602016, 2016, p.16-17.

CARLOS, Ana Fani Alessandri. A (re) produção do espaço urbano. São Paulo: EDUSP, 1994.

SANTO, Sandra Medeiro et al. Estado, política habitacional e expansão urbana no Brasil: utopias democráticas e realidades. In: Colóquio Internacional de Geocrítica: Las utopías y la construcción de la sociedad del futuro, 14, 2016. Anais... Barcelona, 2016. Disponível em: < http://www.ub.edu/geocrit/xiv_medeirosbraga.pdf> Acesso em: 24/06/2017.

PREFEITURA MUNICIPAL DE FEIRA DE SANTANA, Lei Complementar $\mathrm{N}^{\circ}$ 075, de 20 de Junho de 2013. Diário oficial do município. Poder Executivo. Feira de Santana. 20 de jun de 2013. Disponível em: https://leismunicipais.com.br/a/ba/f/feira-de-santana/leicomplementar/2013/7/75/lei-complementar-n-75-2013-fixa-os-limites-interdistritais-ampliao-perimetro-urbano-e-delimita-06-seis-novos-bairros-do-distrito-sede-do-municipio-de-feirade-santana-e-da-outras-providencias> Acesso em: 15/04/2017.

OJIMA, Ricardo. Novos contornos do crescimento urbano brasileiro? O conceito de Urban Sprawl e os desafios para o Planejamento Regional e Ambiental. Geographia, Vol. 10, No 19 (2008). Disponível em: <http://www.uff.br/geographia/ ojs/index.php/geographia/ article/viewArticle/234> Acesso em:15-03-2016. 